\title{
The Expressive and the Receptive One Word Picture Vocabulary test (EOWPVT \& ROWPVT). (A combine pilot study and validation of the tests' in normal Greek population - aged from 18 years till 18 years and 11 months)
}

\author{
Dionisios Tafiadis ${ }^{1,2^{*}}$, Maria Zizika ${ }^{1}$, Maria Tafiadi ${ }^{3}$
}

From $1^{\text {st }}$ International Congress on Neurobiology and Clinical Psychopharmacology and European Psychiatric Association Conference on Treatment Guidance

Thessaloniki, Greece. 19-22 November 2009

\section{Background}

The present pilot study was the adaption and validation of receptive and expressive language tests' for Greek children aged from 18 years till 18 years and 11 months. The 3rd edition (2000) - used in this research - of ROWPVT and EOWPVT was originally created by Rick Brownell in 1985.

\section{Materials and methods}

The commercial versions of the tests were adapted in Greek language by a linguist, three speech language therapists and 2 native speakers of Greek language, having proficiency in English, and two native speakers of English having proficiency in Greek, and changes were contacted, for the best representation of the Greek version. In this research took part 100 participants (m:50, f: 50) recruited from Greek Schools at the region of Ioannina. The sample was independent from origin and socio - economic situations. Also an ENT, neurological and a psychological examination were also requested, so no medical problems could probably influence the test results.

\section{Results}

Statistical analysis of the data revealed that the results obtained are generally consistent other results reported. No statistically significant differences were found according or sex. Also reliability and validity test were contacted and showed high criterion $(\mathrm{a}-$ Chronbach $=$ $.757, \& .798)$.

\section{Conclusions}

The test appears to be sensitive to that age for the Greek population and presents satisfactory criterion, internal consistency, temporal stability, interrater reliability. Also the test showed high content validity, as the participants assessed demonstrated clear patterns of responses, but further changes must be done for the Greek version in clinical and research settings.

\section{Author details}

'Department of Speech and Language Therapy, T.E.I. of Epirus, loannina, Ioanninon, Greece. ${ }^{2}$ Department of Neural Sciences and Sensory Organs (School of medicine), University of loannina, loannina, Ioanninon, Greece. ${ }^{3}$ Department of Mathematics, National and Kapodistrian University of Athens, Athens, Attika, Greece.

Published: 22 April 2010

doi:10.1186/1744-859X-9-S1-S117

Cite this article as: Tafiadis et al:: The Expressive and the Receptive One Word Picture Vocabulary test (EOWPVT \& ROWPVT). (A combine pilot study and validation of the tests' in normal Greek population - aged from 18 years till 18 years and 11 months). Annals of General Psychiatry 2010 9(Suppl 1):S117. 